\title{
ISSUES FOR MEDICAL CENTER RESEARCH
}

\author{
A. L. Chapman \\ Vice Chancellor for Academic Affairs \\ University of Kansas Medical Center
}

In a medical center environment, it is critical to blend both basic (bench) and clinical research. The latter would include the application of new knowledge to the treatment of the patient. Application of new knowledge requires use of industry and business resources in production, manufacturing and distribution.

The initiation of new knowledge depends, in large part, on a strong basic research component in the medical sciences. The major funding for this type of research is generally dependent upon the federal government, particularly the National Institutes of Health (NIH) which approximates $\$ 13.6$ billion in fiscal year 1998. It is of particular interest to comment on a recent report submitted to the NIH suggesting areas for future expenditure. This report was made by the Research and Policy Committee of the Committee on Economic Development in 1998 and was given to Harold Varmus, Director of the NIH. The Committee stated that it is essential to maintain the integral role of government in supporting basic research, as industry continues to focus on research and development with specific product-directed goals.

The Committee reported that:

- The return from basic science to the nation's economy has been substantially higher than the return to private firms;

- Basic research performed at universities is correlated with strong economic activities in their neighbors' locale, e.g., there are more than 1,000 MIT-related companies in Massachusetts with world-wide sales of more than $\$ 53$ billion annually;

- Of some $\$ 63$ billion that government spends on research and development annually, $\$ 18$ billion goes to basic research compared to $\$ 8$ billion spent by industry on basic research from a total of $\$ 133$ billion in research and development funding;

- $73 \%$ of research publications cited by industrial patents were derived from government-related funding;

- The essential strength of the American system is the rigorous peer review process;

- The most important American institutions conducting basic research are the nation's 200 major research universities;

- The biotechnology industry has been the major beneficiary of the Bayh-Dole Act in 1980; 
- University-industry relationships must be managed carefully and according to strict guidelines that protect the primary basic research mission of the universities.

Based on this report, the Committee offered certain principles to NIH for guidance:

- Retain investigator-initiated, competitive, peer-reviewed grants;

- Increase funds for innovative training and research partnerships involving business and industry;

- Incorporate fundamental disciplines including basic scientific and engineering research;

- Revitalize and adequately fund clinical research and its infrastructure, including clinical research centers;

- Expedite movement of new research findings from the laboratory and scientific journals to practicing physicians and their patients;

- Improve support for young investigators, including training grants and individual fellowships;

- Support construction of new facilities for research, particularly focused on sophisticated research equipment and facilities.

Clearly, positioning each of our institutions to take advantage of federal and private grant/contract funds requires changes as well as internal investment. One such initiative at the KU Medical Center included the formation of a non-profit foundation-the KUMC Research Institute-in 1992. Its purpose is to improve working relationships with the private sector, improve service to the faculty, and provide additional sources of revenue through an internal grants program.

Achievements of the KUMC Research Institute include:

- Favorable responses from investigators who appreciate the increased flexibility of grant funding;

- Financial self-sufficiency because the Research Institute does not require state support;

- Development of three divisions: Grants Management, Technology Development and Clinical Trials;

- $\$ 520,000$ disbursed in awards to faculty through the peer-reviewed small grants program in the last fiscal year; 
- 100 invention disclosures received from faculty, including patenting and licensing;

- Formation of six companies based on faculty-derived technology;

- Development and management of a research incubator building;

- Purchase of eight acres of property adjacent to the Medical Center campus and donation of three acres to the state for the Center for Health and Aging Building;

- Potential commercial development of the remainder of the property in support of the research mission;

- Management of 160 clinical trials.

In conclusion, to improve the research environment, it is critical to include a nonprofit foundation as part of research management at the institutional level. However, this is only one small step in addressing the needs of any medical center. It is clearly necessary for research universities to position themselves for growth through expanded funding from federal and private sectors. Those institutions that have demonstrated recent success in increasing their institutional rankings have received a significant influx of funds from state and/or private sources. This has generally resulted in new buildings as well as additional support for the research faculty. 